\title{
Know your standards: Improvement and validation of standard materials for quantitative WDS and EDS analysis
}

\author{
Rosie Jones $^{1}$, Simon Burgess ${ }^{2}$, Philippe Pinard ${ }^{1}$ and Michael Hjelmstad ${ }^{3}$
}

${ }^{1}$ Oxford Instruments NanoAnalysis, High Wycombe, United Kingdom, ${ }^{2}$ Oxford Instruments NanoAnalysis, High Wycombe, England, United Kingdom, ${ }^{3}$ Oxford Instruments Inc, Pleasanton, California, United States

Standard materials of known composition are fundamental to producing and validating quantitative results via X-ray microanalysis. As EDS and WDS are relative techniques, appropriate standards of known composition need to be measured to quantify unknown samples. As such, the quality of the standard material impacts directly on the quality of the quantitative result. Reliable standards materials are not only important for standard-based quantification via EDS and/or WDS, where the user collects calibrations on their own standard materials, but also for the development of standardless methods, where the calibration of each element is done by the system developer/manufacturer [1]. Standard materials are also used to validate the accuracy of the results produced by a system. These standards are sometimes referred to as 'secondary standards' and they are often measured routinely alongside samples/unknowns. The reproducibility of the secondary standard results (i.e., precision), and differences between the measured and published compositions (i.e., accuracy), are used to evaluate the size of the errors in the results from unknown samples.

A problem arises that many of the standards available for X-ray microanalysis, particularly complex standards such as minerals, are characterized by EDS/WDS in the first instance, and it is difficult to find examples where the published composition has been determined/verified using another method (e.g., wet chemistry). This is a particular problem for analysts who use complex standards of similar composition to minimize matrix affects, as these standards are likely to have been characterized using other similar composition complex standards with the same verification issues, or with simple standards with associated matrix correction uncertainties that the analyst is trying to avoid. Therefore, a methodology is required to validate compositions of complex standards, and a potential approach was outlined in a paper presented last year [2]. The work presented here expands on that paper and aims to validate the proposed method.

The methodology that we have tested, to validate complex standards (e.g., natural minerals), is based on choosing simple primary standards (e.g., pure elements, stoichiometric binary compounds), and analytical conditions that minimize matrix corrections for the complex standard being verified. To achieve this, we have evaluated the level of matrix correction between many different potential standard materials, including pure elements, binary compounds, and the complex natural minerals (Fig. 1). To minimize the potential of errors in the matrix correction, we have chosen primary standards where the matrix correction is as small as possible, with the aim of using a matrix correction between 0.9 and 1.1 (where a value of 1 equals no matrix correction). Minimizing the matrix correction also required careful selection of accelerating voltage. Each standard material has been analyzed at different accelerating voltages to check the sensitivity of the measured composition with changing matrix correction, and to further investigate possible matrix correction errors. For example, Figure 2 shows the results for the minerals orthoclase and forsterite analyzed using a Wave WDS spectrometer (elements >1 wt.\%) and an Ultim Max $170 \mathrm{~mm} 2$ 
EDS detector (elements < 1 wt.\%). The combined EDS-WDS data was collected and quantified in the AZtecWave software platform. The following primary standards were used: Al2O3 (Al), SiO2 ( $\mathrm{Si}$ ), $\mathrm{KBr}$ $(\mathrm{K}), \mathrm{MgO}(\mathrm{Mg})$, pure $\mathrm{Fe}$ and $\mathrm{Fe} 2 \mathrm{O} 3(\mathrm{Fe})$, and were acquired at multiple accelerating voltages $(10,15$, and $20 \mathrm{kV}$ ). Oxygen was calculated by stoichiometry and the analytical totals were un-normalized. Comparisons were made between the measured and published concentrations of the major elements at different accelerating voltages. As seen in Figure 2, the largest variation in concentration (wt.\%) is seen in $\mathrm{Al}$ (orthoclase) and $\mathrm{Mg}$ (forsterite). However, statistical analysis (t-test) suggests that the changes observed here are not statistically significant ( $\mathrm{Al}$ p-value $=0.062$ and $\mathrm{Mg} \mathrm{p}$-value $=0.010$ ), meaning the null hypothesis of identical averages cannot be rejected. To further validate the accuracy of the composition, cation totals were calculated to check they were consistent with the mineral formula both for the total and for each cation site. Our aim is to achieve totals within 0.01 of the expected value for each site. For the examples presented we achieved this for the formula total, but some cation sites were only within 0.02 of expected. Sources of error continue to be investigated and may be related to the analytical set-up (e.g., uncertainty in carbon coat thickness and surface tilt of the standards), as well as the matrix corrections themselves.

This follow-up study has increased our confidence that the proposed method can be used to validate complex minerals for use as both standards for EDS and/or WDS calibration, and for secondary validation standards, provided a suitable set of simple primary standards and analytical conditions can be found that keep matrix corrections small. With an increasing library of validated complex standards, we can standardize using standards of similar compositions for more applications and achieve more confident determination of the composition of new standard materials.

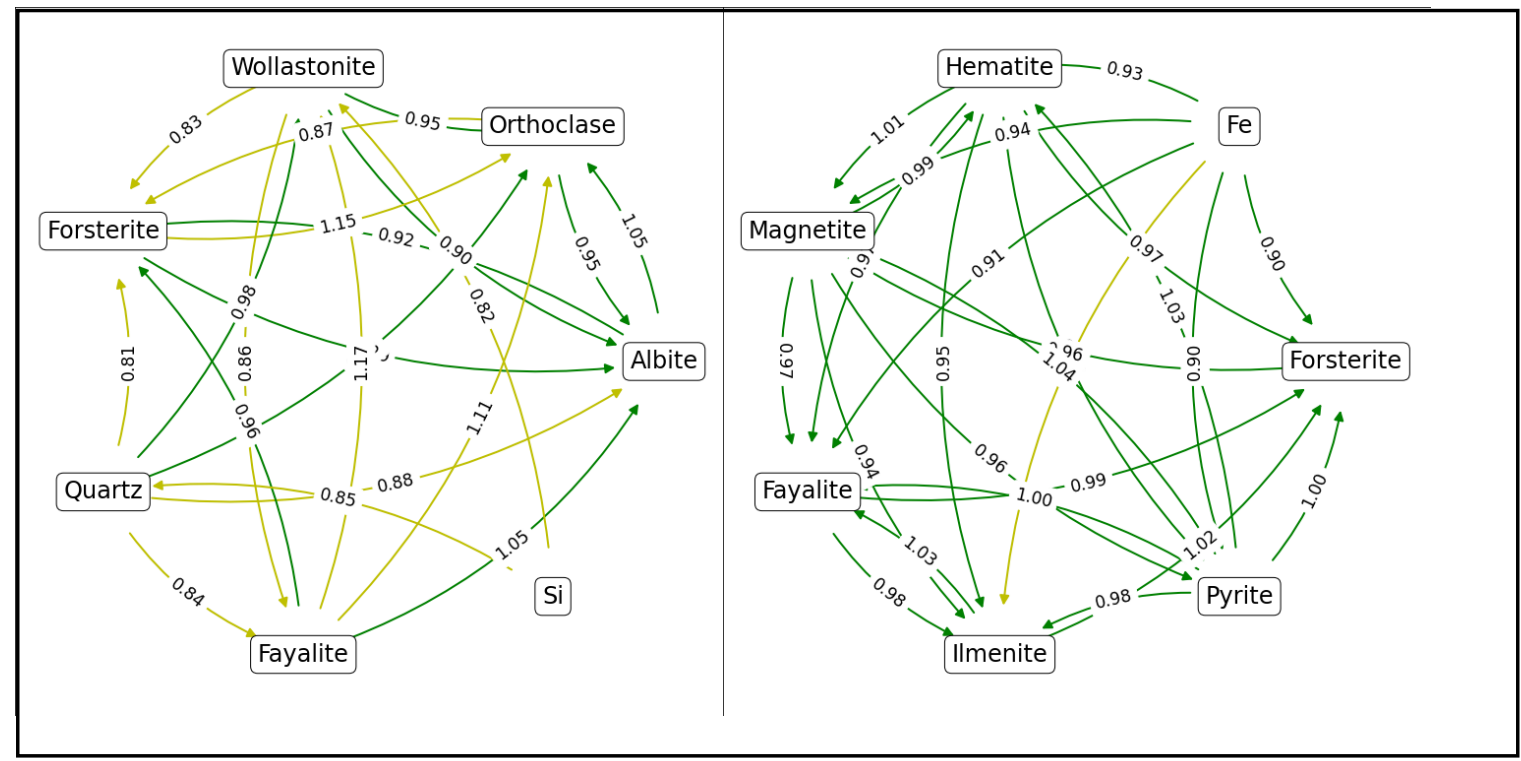

Figure 1. Plots showing the matrix correction between different mineral standards, for $\mathrm{Si}$ at $15 \mathrm{kV}$ (left) and $\mathrm{Fe}$ at $20 \mathrm{kV}$ (right). The mineral standards presented for $\mathrm{Si}$ are quartz $\left(\mathrm{SiO}_{2}\right)$, fayalite $\left(\mathrm{Fe}_{2} \mathrm{SiO}_{4}\right)$, forsterite $\left((\mathrm{Mg}, \mathrm{Fe})_{2} \mathrm{SiO}_{4}\right)$, wollastonite $\left(\mathrm{CaSiO}_{3}\right)$, albite $\left(\mathrm{NaAlSi}_{3} \mathrm{O}_{8}\right)$ and orthoclase $\left(\mathrm{KAlSi}_{3} \mathrm{O}_{8}\right)$, and for $\mathrm{Fe}$ are hematite $\left(\mathrm{Fe}_{2} \mathrm{O}_{3}\right)$, magnetite $\left(\mathrm{Fe}_{3} \mathrm{O}_{4}\right)$, ilmenite $\left(\mathrm{FeTiO}_{3}\right)$, fayalite $\left(\mathrm{Fe}_{2} \mathrm{SiO}_{4}\right)$, forsterite $\left((\mathrm{Mg}, \mathrm{Fe})_{2} \mathrm{SiO}_{4}\right)$, and pyrite $\left(\mathrm{FeS}_{2}\right)$. Each arrow and their inscribed value indicates the matrix correction between a standard (start) and an unknown (end), where a value of 1 equals no matrix correction. For 
example, $\mathrm{SiO} 2 \rightarrow$ Forsterite is the matrix correction if $\mathrm{SiO} 2$ was used as the standard to quantify the $\mathrm{Si}$ content in Forsterite. Matrix corrections between 0.9 and 1.1 are drawn in green. Matrix corrections below 0.8 are not shown.
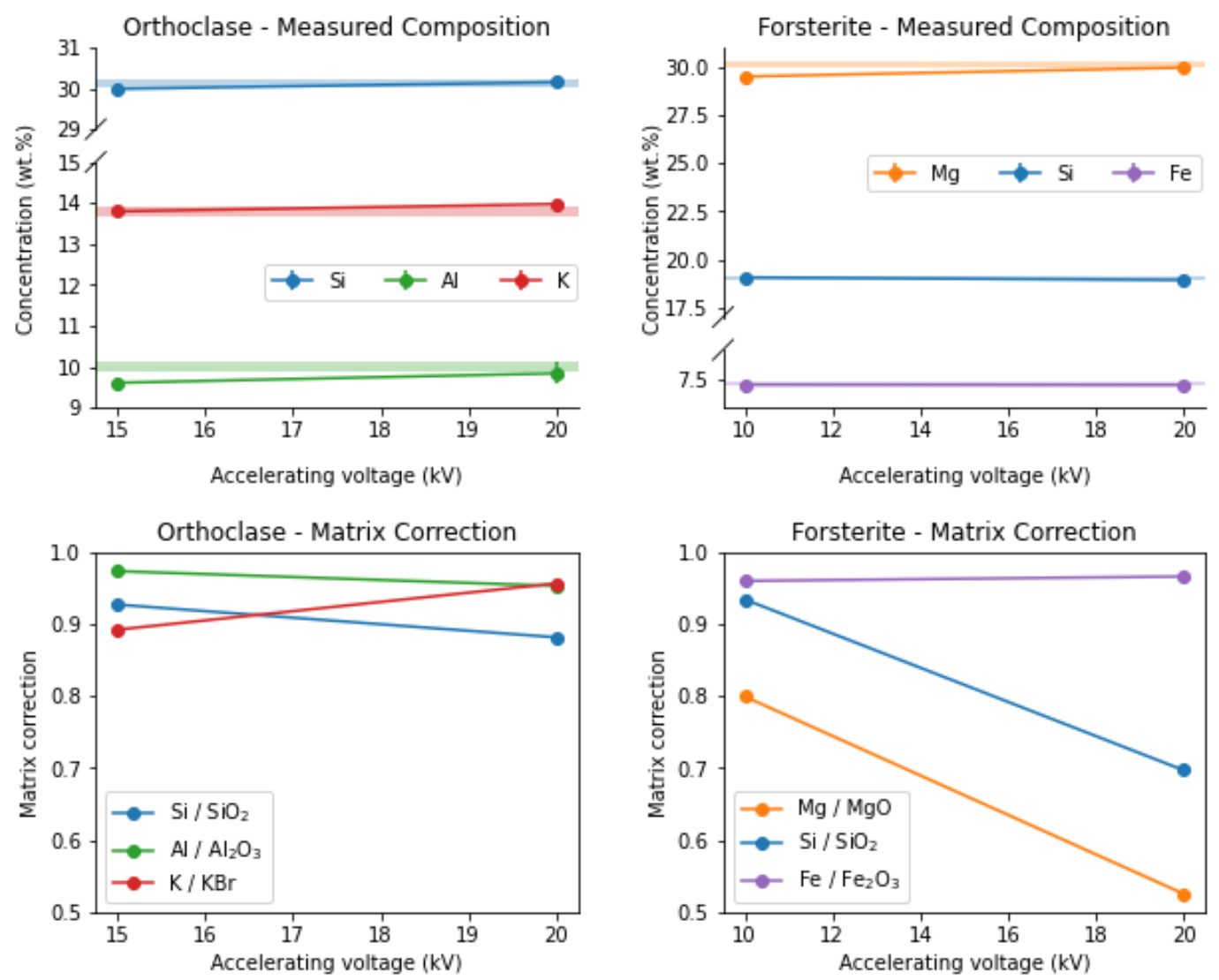

Figure 2. Calculated compositions and matrix corrections for $\mathrm{Al}, \mathrm{Si}$, and $\mathrm{K}$ in orthoclase (left) and $\mathrm{Mg}$, $\mathrm{Si}$, and $\mathrm{Fe}$ in forsterite (right) measured using WDS at different accelerating voltages. Compositions are compared to expected compositional bands calculated from the certificate composition of each standard and their measured heterogeneity. "Matrix Correction" is the ratio of factors for sample and standard.

\section{References}

[1] Pinard, P.T., Protheroe, A., Holland, J., Burgess, S. and Statham, P.J., 2020, July. Development and validation of standardless and standards-based X-ray microanalysis. In IOP Conference Series: Materials Science and Engineering (Vol. 891, No. 1, p. 012020). IOP Publishing.

[2] Burgess, S., Pinard, P., Kearns, S., Buse, B., Dyson, H., \& Jones, R. (2020). Can the ISO 14595 Method be Used to Validate the Heterogeneity and Composition of Natural Mineral Standards Using WDS And/or EDS? Microscopy and Microanalysis, 26(S2), 1778-1780. doi:10.1017/S1431927620019315 